Revista Universo Contábil, ISSN 1809-3337

Blumenau, v. 7, n. 3, p. 59-76, jul./set., 2011

doi:10.4270/ruc.2011322

Disponível em www.furb.br/universocontabil

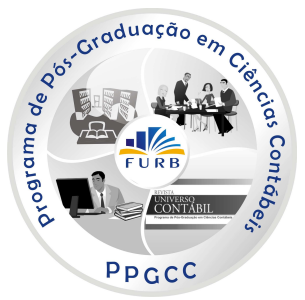

PARADOXO NA UTILIZAÇÃO DE ARTEFATOS CONTÁBEIS GERENCIAIS: DISCUSSÃO SOBRE A INFLUÊNCIA DE FATORES INCONSCIENTES INSPIRADA EM CONCEITOS PRECONIZADOS PELA PSICOLOGIA ANALÍTICA ${ }^{1}$

\title{
PARADOX OF USING MANAGEMENT ACCOUNTING ARTIFACTS: A DISCUSSION ON THE INFLUENCE OF UNCONSCIOUS FACTORS INSPIRED IN THE CONCEPTS PRECONIZED BY THE ANALYTICAL PSYCHOLOGY
}

Flaviano Costa

Mestre em Contabilidade pela Universidade Federal do Paraná - UFPR Professor da Faculdade de Ciências Sociais e Aplicadas do Paraná - FACET

Endereço: Av. Manoel Ribas, 4535 - casa 01 CEP: 82020-000 - Curitiba/PR - Brasil

E-mail: flaviano_costa@hotmail.com Telefones: (41) 3335-4742

Ana Paula Capuano da Cruz

Doutoranda em Controladoria e Contabilidade pela FEA/USP

Endereço: Alameda Uruguay, 55 CEP: 96203-040 - Rio Grande/RS - Brasil E-mail: anapaulacapuanocruz@hotmail.com Telefones: (53) 3230-2417

\begin{abstract}
Márcia Maria dos Santos Bortolocci Espejo
Doutora em Controladoria e Contabilidade pela Universidade de São Paulo - FEA/USP Professora do Mestrado em Contabilidade da Universidade Federal do Paraná - UFPR

Endereço: Av. Prefeito Lothário Meissner, 632/1ำ andar CEP: 80210-170 - Curitiba/PR - Brasil E-mail: marciabortolocci@ufpr.br Telefones: (41) 3360-4417
\end{abstract}

\section{RESUMO}

O presente ensaio foi desenvolvido com a finalidade de fornecer elementos que contribuam para um melhor entendimento da postura do profissional contábil, que possam elucidar algumas possíveis razões do paradoxo existente entre o conhecimento teórico e a adoção dos

\footnotetext{
1 Artigo recebido em 15.09.2010. Revisado por pares em 18.11.2010. Reformulado em 10.01.2011. Recomendado para publicação em 20.01.2011 por Ilse Maria Beuren (Editora). Publicado em 30.09.2011. Organização responsável pelo periódico: FURB.
} 
artefatos contábeis gerenciais, por meio de fatores inconscientes, sob a inspiração dos conceitos preconizados pela psicologia analítica. Por meio da análise crítico-reflexiva realizada, ponderou-se que [1] a contabilidade gerencial possui hábitos e rotinas repetitivas e mecanicistas, constituindo um inconsciente coletivo próprio, dominado por arquétipos, difíceis de serem modificados; [2] os arquétipos junguianos persona e sombra representam as informações evidenciadas ou sonegadas, respectivamente, em contabilidade gerencial; [3] os arquétipos junguianos anima e animus demonstram as relações de gênero em contabilidade gerencial; [4] o self é demonstrado como o ponto de decisão constantemente buscado. Destaca-se também que o presente ensaio teórico possui implicações acadêmicas e profissionais para a ciência contábil, no que tange à postura do contador no processo de tomada de decisão.

Palavras-chave: Contabilidade gerencial. Artefatos contábeis gerenciais. Fatores inconscientes. Psicologia analítica.

\section{ABSTRACT}

This paper was developed in order to provide elements that contribute to a better understanding of the accounting professional posture, which may elucidate some possible reasons for the existent paradox between the theoretical knowledge and the adoption of management accounting artifacts, through unconscious factors, under the inspiration of the concepts preconized by the analytical psychology. Through the critical-reflective analysis performed, it was pondered that: [1] in the managerial accounting there are repetitive and mechanistic habits and routines, constituting its own collective unconscious, dominated by archetypes, difficult to be modified; [2] Jung's archetypes The persona and The shadow represent the disclosed or withheld information, respectively, in management accounting; [3] Jung's The anima and The animus archetypes show the gender relations in management accounting; [4] The self is shown as the decision point constantly sought. It is also noteworthy that the present theoretical paper has academic and professional implications for the accounting science, regarding the posture the accountant in the decision-making process.

Keywords: Management accounting. Management accounting artifacts. Unconscious factors. Analytical psychology.

\section{INTRODUÇÃO}

Muito se tem escrito sobre contabilidade gerencial e sua importância crescente no cenário contemporâneo devido às constantes transformações pelas quais passa o mundo corporativo. Seguindo esse raciocínio, Espejo (2008, p. 11) afirma que, "a busca pela continuidade dos negócios exige habilidade e competência de gestores envolvidos em profundas mudanças tecnológicas, pela rapidez da informação, relações comerciais tensas e por um ambiente cada vez mais competitivo e incerto". Complementarmente, algumas pesquisas trazem à reflexão uma questão veemente nos estudos gerenciais, o aparente paradoxo existente entre a teoria e prática na utilização dos artefatos contábeis gerenciais (GRANLUND, 2001; GUERREIRO; FREZATTI; CASADO, 2006). Guerreiro, Frezatti e Casado (2006, p. 7) afirmam que, "apesar de fatores indutores e facilitadores do ambiente externo, o que se observa é o baixo grau de implementação de novas técnicas e conceitos de contabilidade gerencial nas empresas".

$\mathrm{O}$ estudo de teorias alternativas que incorporem um maior número de variáveis à compreensão da contabilidade gerencial ainda merece maior atenção por parte dos 
pesquisadores, visto que a racionalidade econômica limita o entendimento dos processos organizacionais por não ser a única teoria que respalda o processo decisório nas entidades (ITTNER; LARCKER, 2002). Nesse sentido, Otley (1994) esclarece que as suposições e a linguagem usada no paradigma tradicional de controle gerencial estão ficando distantes da realidade dos assuntos e problemas nos negócios atuais, sendo impróprias e ineficazes na manutenção da boa estrutura organizacional.

Uma forma diferenciada de estudos organizacionais tem sido a utilização de conceitos próprios da psicologia no entendimento do comportamento humano. Investigações internacionais têm sido realizadas com base nos estilos cognitivos para explicar o processo de tomada de decisão (ALLINSON; HAYES, 1996; GARDNER; MARTINKO, 1996; CHENG; LUCKETT; SCHULZ, 2003; HOUGH; OGILVIE, 2005; GALLÉN, 2006; HALL, 2008). Tais pesquisas utilizam-se da psicologia para clarificar fatores comportamentais relacionados com o processo de gestão empresarial, corroborando com a já mencionada utilização de teorias alternativas à econômica para elucidar o processo decisório. No Brasil percebe-se que a exploração dessa interação entre a psicologia e a contabilidade gerencial ainda é incipiente, com escassos estudos referenciados (GUERREIRO; CASADO; BIO, 2004; GUERREIRO; FREZATTI; CASADO, 2006; SANTOS; ALMEIDA; CROZATTI, 2007; ESPEJO et al., 2009). Tendo em vista essa carência de estudos nacionais, este ensaio desenvolve uma discussão acerca do ambiente da contabilidade gerencial por meio dos preceitos junguianos ou da chamada psicologia analítica.

Como consequência dos pressupostos anteriormente mencionados, a questão orientadora do presente estudo é a seguinte: A análise de fatores inconscientes, inspirada em conceitos preconizados pela psicologia analítica, pode contribuir para a compreensão da postura do profissional contábil, especialmente no que diz respeito às causas do descompasso existente entre as concepções teóricas e a adoção de artefatos de contabilidade gerencial? $\mathrm{O}$ objetivo subjacente nesse enunciado é fornecer elementos que contribuam para um melhor entendimento da postura do profissional contábil, que possam elucidar possíveis razões do paradoxo existente entre o conhecimento teórico e a adoção dos artefatos contábeis gerenciais, por meio dos fatores inconscientes, sob a inspiração dos conceitos junguianos. Assim posto, a proposta é desenvolver uma análise crítica explorando as bases epistemológicas dos principais estudos que respaldam a discussão proposta, estimulando um processo reflexivo acerca de elementos relacionados à postura do profissional contábil diante da adoção dos artefatos contábeis gerenciais. Porquanto, a teoria crítica "chama a atenção, por exemplo, para a estreiteza do pensamento associado ao domínio da razão instrumental e do código do dinheiro" (ALVESSON; DEETZ, 2007, p. 244).

Salienta-se que não se tem a pretensão de esgotar o assunto colocado em discussão e nem potencializar fatores inconscientes do indivíduo como única forma de explicação do gap existente entre teoria e prática no uso dos artefatos contábeis gerenciais, a intenção é discutir elementos, de certa forma pouco vislumbrados, fornecendo visões diferentes e novas formas de definir a realidade dos fatos, contribuindo para o entendimento da diversidade de mundos possíveis nos estudos em contabilidade gerencial e, consequentemente, para a sua melhor compreensão. Desse modo, esta investigação classifica-se metodologicamente como um ensaio teórico.

O ensaio está estruturado em mais cinco seções. Nas três próximas seções apresenta-se o referencial teórico, contemplando a contabilidade gerencial e seus artefatos, a problemática do descompasso existente entre o conhecimento teórico e a utilização prática dos artefatos de contabilidade gerencial, e os conceitos junguianos explorando-se subsídios para a compreensão de aspectos relacionados à psicologia analítica. Na seção seguinte, à luz do estudo dos fatores inconscientes, é traçado um paralelo e uma análise crítico-reflexiva entre a contabilidade gerencial e o "Mito da Caverna" de Platão, os arquétipos da persona, da 
sombra, do anima, do animus e o self, adicionando-se novos elementos à reflexão. Por fim, na última seção, são expostas as considerações finais do estudo desenvolvido, na qual são apresentadas as implicações acadêmicas e profissionais da discussão e também são sugeridas pesquisas futuras sobre a temática discutida.

\section{CONTABILIDADE GERENCIAL E SEUS ARTEFATOS}

A contabilidade gerencial caracteriza-se por identificar, mensurar, acumular, analisar, preparar, interpretar e comunicar informações aos gestores para a tomada de decisões, contribuindo ao sucesso dos objetivos organizacionais (HORNGREN; SUNDEN; STRATTON, 1996). Analogamente à amplitude da contabilidade gerencial sugerida por Horngren, Sunden e Stratton (1996); Otley (1994, p. 294) afirma que essa ramificação contábil "é a principal ferramenta de controle do processo de gestão". De forma a complementar essas informações, Atkinson et al. (2008) esclarecem que as informações geradas pela contabilidade gerencial são importantes para todos os indivíduos da organização por reunirem elementos que evidenciam o desempenho organizacional por meio de um processo de retroalimentação pelo qual essas pessoas apreendem as experiências passadas para melhorarem ações futuras. Observando-se os estudos realizados em contabilidade gerencial, verifica-se que na maioria das pesquisas há um ponto convergente, de que as informações geradas pelos artefatos contábeis gerencias devem ser relevantes à tomada de decisão do gestor. Em conformidade com essa linha argumentativa, Padoveze (2003, p.9) explicita que "a contabilidade gerencial mudou o foco da contabilidade, passando dos registros e análise das transações financeiras para a utilização da informação para decisões, afetando o futuro".

De acordo com Espejo (2008, p. 12), “os artefatos contábeis servem como facilitadores do alcance dos objetivos organizacionais, que a priori baseiam-se na otimização dos recursos, numa perspectiva de resultados de longo prazo". Comumente artigos, dissertações e teses têm utilizado a expressão "artefatos" contábeis gerenciais (FREZATTI, 2005; SOUTES, 2006; SOUTES; GUERREIRO, 2007; ESPEJO, 2008; OYADOMARI et al., 2008; ESPEJO et al., 2009). Há também aqueles pesquisadores que recorrem a termos como "técnicas, ferramentas ou instrumentos" contábeis gerenciais (SOUZA; LISBOA; ROCHA, 2003; GUERREIRO et al., 2005). Contudo, considera-se que o termo "artefatos" seja mais completo, pois, conforme Frezatti (2006, p.36), os artefatos contábeis indicam "conceitos, sistemas e ferramentas contábeis" essenciais à gestão empresarial. Contribuindo para esse entendimento, Soutes e Guerreiro (2007, p. 2) mencionam que artefatos contábeis gerenciais são as "atividades, ferramentas, instrumentos, filosofias de gestão, filosofias de produção, modelos de gestão e sistemas que possam ser utilizados pelos profissionais da contabilidade gerencial no exercício de suas funções".

Os artefatos contábeis gerenciais, em sua maioria, surgiram da tentativa de se recuperar a relevância da contabilidade gerencial após os estudos de alguns pesquisadores, dentre os quais se destaca Johnson e Kaplan (1987). Desse modo vários artefatos surgiram ou foram desenvolvidos. Como exemplos, podem-se citar o ABC (Activity Based Costing), Custeio Meta (Target Costing), EVA (Economic Value Added), entre outros, que Baines e Langfield-Smith (2003) classificam como sendo práticas de contabilidade gerencial avançadas.

\section{O DESCOMPASSO: CONHECIMENTO TEÓRICO X UTILIZAÇÃO PRÁTICA}

Ponderando as exposições realizadas, e a consideração feita por Lopes (2004, p. 185), de que "ignorar o contexto organizacional é esquecer a própria essência e razão de ser da contabilidade", no Brasil a temática sobre estabilidade e mudança nos sistemas contábeis 
gerenciais tem sido pouco explorada em contraposição às pesquisas desse gênero em outros países, principalmente na Europa (GUERREIRO et al., 2005). O que se vê é que apesar do avanço dos artefatos contábeis gerenciais, a maioria das organizações não os utiliza como fonte de informações para a tomada de decisões. Diversos estudos foram realizados na tentativa de elucidar esse gap existente entre o conhecimento teórico dessas técnicas e a utilização prática (JOHNSON; KAPLAN, 1987; COVALESKI et al., 1996; GRANLUND; LUKKA, 1998; BURNS; SCAPENS, 2000; GRANLUND, 2001; FREZATTI, 2005; SOUTES, 2006). Muitos desses estudos baseiam-se na teoria institucional como tentativa de explicar esse descompasso entre a teoria e a prática na utilização de artefatos contábeis.

Baines e Langfield-Smith (2003) afirmaram que as mudanças no ambiente externo à organização influenciam no estudo de novas técnicas e alternativas para a contabilidade gerencial. Isso ocorre porque a contabilidade gerencial fornece informações para a tomada de decisões e deve acompanhar alterações do cenário externo. Nesse sentido, Burns e Scapens (2000, p. 21) esclarecem que, "se queremos que coisas permaneçam como estão, coisas terão que mudar". Granlund (2001) afirma que mesmo diante das evoluções significativas pelas quais as técnicas contábeis têm passado, é difícil mudar um sistema contábil gerencial nas organizações, contribuindo assim, à formação de um paradoxo entre o conhecimento e a aplicação, ainda que as mudanças no mercado pressionem a contabilidade a essa transformação.

$\mathrm{O}$ que se percebe nas investigações citadas é que a contabilidade torna-se uma instituição dentro da entidade e difícil de ser modificada, visto que a prática contábil constituise em rotinas e hábitos legitimados na organização, refutando assim, a abordagem puramente baseada na racionalidade econômica. Confirmando essa assertiva, Guerreiro, Frezatti e Casado (2006, p. 12) asseguram que, "a Contabilidade Gerencial como uma instituição corresponde a um conjunto de rotinas institucionalizadas e aceitas na organização, devendo-se observar que a Contabilidade Gerencial tanto é moldada quanto impacta em outras instituições no âmbito da organização".

Recorrendo a Oliver (1991), o ponto central da teoria institucional é que o ambiente exerce poderosa influência no processo adaptativo às regras organizacionais, de modo que, dependendo do grau de institucionalização haverá maior ou menor margem para resistência à mudança, sugerindo assim, que quanto maior o grau de legitimação dessas rotinas e hábitos, mais difícil será a implantação dos artefatos contábeis gerenciais no ambiente da contabilidade gerencial. Nesse sentido, pode-se supor que esses hábitos e rotinas institucionalizados nas organizações são permeados por fatores inconscientes, devido ao automatismo com que são executados.

Quellette e Wood (1998) estudaram à luz da psicologia cognitiva as rotinas no interior das organizações e afirmam que os velhos hábitos são difíceis de serem modificados por ocasião da velocidade e facilidade com que esses padrões de comportamento podem ser executados. De acordo com esses autores, os padrões comportamentais passados que se institucionalizaram na organização por meio de hábitos repetitivos e automáticos, tornam-se inconscientes, formando estruturas de certa forma "arquetípicas" no ambiente empresarial.

Portanto, pode-se depreender que os fatores inconscientes sugerem uma influência na postura do profissional contábil que, em última instância, decide sobre a escolha e aplicação de determinado artefato contábil gerencial, podendo ser uma fonte de explicação para esse gap existente entre a diversidade de técnicas e sua efetiva aplicação nas organizações.

\section{INCONSCIENTE E PSICOLOGIA ANALÍTICA}

A psicologia do inconsciente ou ainda, psicologia profunda, como também é denominada, foi estudada desde a antiguidade por diversos filósofos, psiquiatras e psicólogos, antes mesmo que se falasse na teoria psicanalítica de Freud ou na teoria analítica de Jung. O 
Quadro 1 reúne alguns pensamentos que influenciaram sobremaneira Jung a criar um modelo de personalidade complexa por meio da psicologia analítica.

\begin{tabular}{|c|c|}
\hline PESQUISADORES & ÁREA DE ESTUDOS SOBRE O INCONSCIENTE \\
\hline $\begin{array}{l}\text { Gottfried Wilheln von Leibniz } \\
(1646-1716)\end{array}$ & Monadologia - limiar de consciência. \\
\hline $\begin{array}{l}\text { Johann Friedrich Herbart } \\
(1776-1841)\end{array}$ & $\begin{array}{l}\text { Mostrou o aspecto dinâmico da mente; revelou que há uma luta entre as } \\
\text { idéias e que algumas idéias ficam no limiar da consciência; fortaleceu a } \\
\text { construção de associações. }\end{array}$ \\
\hline $\begin{array}{l}\text { Johann Joseph Gasnner } \\
(1727-1779)\end{array}$ & Estudou o agente espiritual. \\
\hline $\begin{array}{l}\text { Franz Anton Mesmer } \\
(1734-1815)\end{array}$ & Estudou o fluido animal. \\
\hline $\begin{array}{l}\text { Abbé Faria } \\
(1746-1819)\end{array}$ & Fez a Teoria Animista e estudou as influências do transe magnético. \\
\hline $\begin{array}{l}\text { Marquês de Puységur } \\
(1751-1825)\end{array}$ & Estudou o sono magnético. \\
\hline $\begin{array}{l}\text { James Braid } \\
(1795-1860)\end{array}$ & Estudou o processo de hipnose. \\
\hline $\begin{array}{l}\text { Friederich Wilheiln Joseph } \\
\text { von Schelling } \\
(1775-1854)\end{array}$ & $\begin{array}{l}\text { Influenciou os pensamentos de Jung e deixou a seguinte frase: "a natureza } \\
\text { deve ser o espírito visível, o espírito a natureza invisível". }\end{array}$ \\
\hline $\begin{array}{l}\text { G. H. von Schubert } \\
(1780-1860)\end{array}$ & $\begin{array}{l}\text { Influenciou Freud, iniciou os estudos sobre os mitos e dividiu o homem em: } \\
\text { corpo, alma e espírito. }\end{array}$ \\
\hline $\begin{array}{l}\text { Justinus Kerner } \\
(1786-1862)\end{array}$ & Combinava exorcismo com magnetismo, influenciou a Parapsicologia. \\
\hline $\begin{array}{l}\text { Carl Gustav Carus } \\
(1789-1869)\end{array}$ & $\begin{array}{l}\text { Influenciou Jung e fez a primeira sistematização de uma teoria para o } \\
\text { inconsciente, descreveu as funções criativas, autônomas e curativas do } \\
\text { inconsciente. }\end{array}$ \\
\hline $\begin{array}{l}\text { Gustav Theodor Fechner } \\
(1801-1887)\end{array}$ & $\begin{array}{l}\text { Influenciou Freud e reproduziu a metáfora do Iceberg que determinava que } \\
\text { a ponta do Iceberg é a consciência, porém, toda a maior parte submersa é } \\
\text { domínio do inconsciente. }\end{array}$ \\
\hline $\begin{array}{l}\text { Arthur Schopenhauer } \\
(1788-1860)\end{array}$ & Influenciou Jung e escreveu um tratado sobre o inconsciente. \\
\hline $\begin{array}{l}\text { Edward von Hartmann } \\
(1842-1906)\end{array}$ & Dividiu o inconsciente em três níveis: absoluto, fisiológico e psicológico. \\
\hline $\begin{array}{l}\text { Karl Albert Scherner } \\
(1825-1889)\end{array}$ & Foi o primeiro a estudar os sonhos. \\
\hline $\begin{array}{l}\text { Jean-Martin Charcot } \\
(1835-1893)\end{array}$ & Estudou a histeria por meio da hipnose. \\
\hline $\begin{array}{l}\text { Frederick Myers } \\
\text { (século XIX) }\end{array}$ & Estudou a função mitopoética do inconsciente. \\
\hline $\begin{array}{l}\text { Pierre Janet } \\
(1859-1947)\end{array}$ & $\begin{array}{l}\text { Cunhou o termo "subconsciente" e é considerado o elo de ligação entre os } \\
\text { estudos do inconsciente do passado e o século XX. }\end{array}$ \\
\hline
\end{tabular}

Quadro 1 - Estudos realizados sobre o Inconsciente antes de Freud e Jung

Fonte: elaborado com base em Ellenberger (1970) e Young-Eisendrath e Dawson (2002).

De acordo com Jung (2008), o inconsciente é o elemento inicial do qual brota a consciência, sendo que as funções básicas e mais importantes de natureza instintiva de qualquer pessoa são inconscientes e a consciência quase que um produto dessa grande área ainda obscura e de difícil entendimento.

A psicologia analítica, representativa de uma divisão da psicanálise, surge quando Jung discorda dos conceitos de seu mestre Sigmund Freud (1856 - 1939) e rompe com a teoria psicanalítica clássica, criando sua própria teoria psicanalítica e seu próprio método de psicoterapia, denominado psicologia analítica. A principal causa dessa ruptura é o fato de Jung não compartilhar e rejeitar o chamado pansexualismo de Freud. Numa análise mais detalhada da ruptura de Jung com Freud, Young-Eisendrath e Dawson (2002) expõem que as 
divergências de opinião entre os dois pensadores deram-se devido às discussões sobre a libido e suas alterações. Nas interpretações de Jung (2008, p. 118), para Freud "o inconsciente é antes de tudo um receptáculo para coisas reprimidas [...] para mim ele se apresenta como um vasto armazenamento histórico".

Parte do inconsciente para Jung (2008, p. 35) consiste em "uma profusão de pensamentos, imagens e impressões provisoriamente ocultos e que, apesar de terem sido perdidos, continuam a influenciar nossas mentes conscientes". Segundo a psicologia analítica, a personalidade total é formada por diversas estruturas diferenciadas, mas que interagem entre si constantemente. Essas estruturas são: [1] o ego ou mente consciente; [2] o inconsciente pessoal e seus complexos; [3] o inconsciente coletivo e seus arquétipos (a anima, o animus, a sombra e a persona); [4] as atitudes de introversão e extroversão; [5] as funções do pensamento, do sentimento, da sensação e da intuição e; [6] o centro de toda a personalidade, denominada self. A Figura 1, inspirada em conceitos preconizados pela psicologia analítica, ilustra, de forma simplificada, a estrutura geral da personalidade.

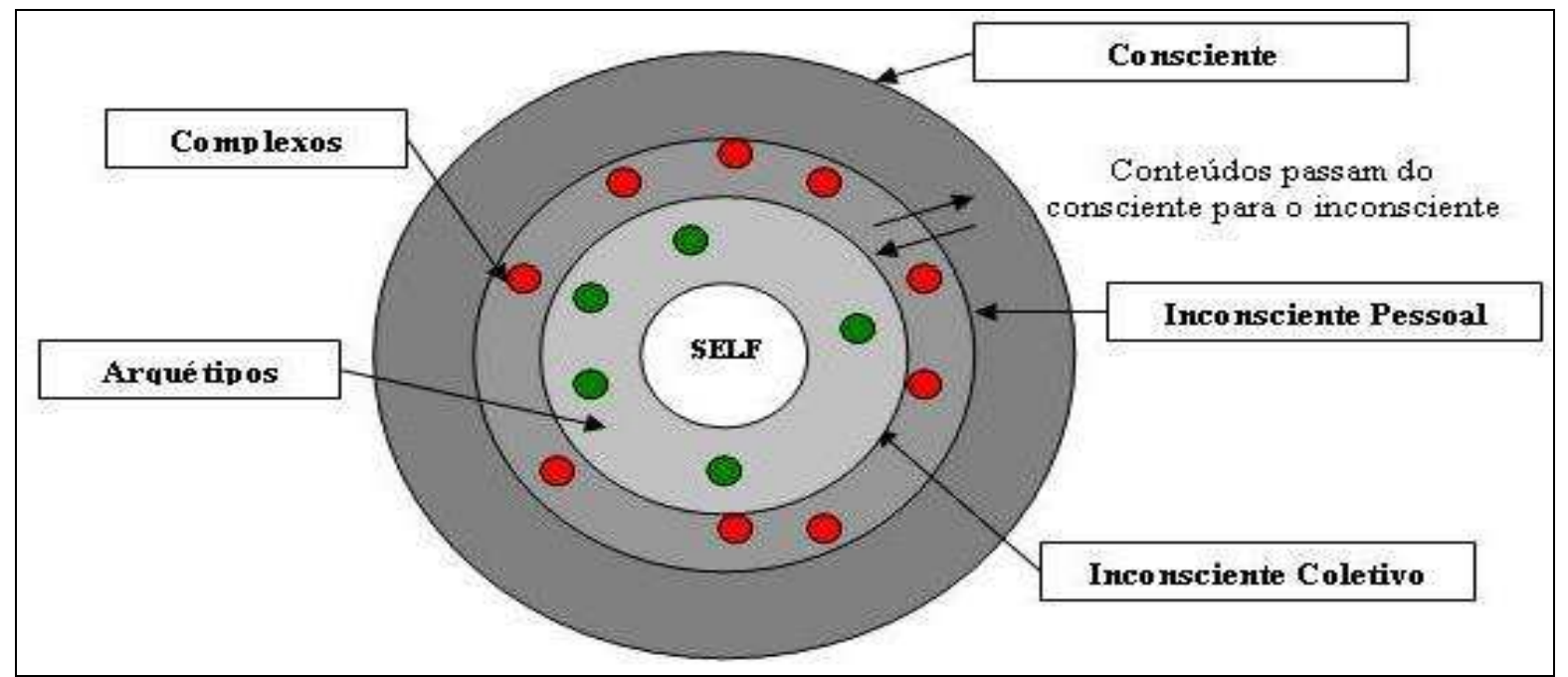

Figura 1 - Estrutura da personalidade

Fonte: elaborada com base em Hall, Lindzey e Campbel (2000), Young-Eisendrath e Dawson (2002).

O ego ou mente consciente é formado por "percepções, memórias, pensamentos e sentimentos conscientes; é responsável pelos nossos sentimentos de identidade e de continuidade, e, do ponto de vista do indivíduo, considera-se que esteja no centro da consciência" (HALL; LINDZEY; CAMPBELL, 2000, p. 88). Contudo, esse conceito referese à mente racional, onde são tomadas decisões ou realizadas escolhas de forma consciente, ao passo que o presente estudo tem como objetivo principal a reflexão acerca dos fatores inconscientes, aqueles que se processam na mente emocional (GOLEMAN, 2001). Para Jung (2008), o homem só atinge o grau de consciência plena quando se liberta dos atavismos ancestrais que o acompanham por meio dos arquétipos que carrega, ou seja, quando consegue diluir todos os seus conteúdos inconscientes que o fazem agir e pensar de modo sistemático e repetitivo, sem o domínio pleno das emoções, alcançando o que denominou estado numinoso.

\subsection{Inconsciente Pessoal, Inconsciente Coletivo e Arquétipos}

De acordo com Jung (2007), o inconsciente pessoal é constituído de conteúdos adquiridos durante a existência do indivíduo, cuja estrutura contém experiências reprimidas, suprimidas, esquecidas ou ignoradas que já fizeram parte da mente consciente, ou componentes que ainda não alcançaram o limiar dessa consciência e constituirão futuros conteúdos na mente consciente. Sendo uma camada adjacente ao ego, os conteúdos do 
inconsciente pessoal podem volver à consciência, existindo um trânsito em via dupla do ego para o inconsciente pessoal. Em resumo, a estrutura pessoal do inconsciente é formada por "todo o material psíquico que subjaz ao limiar da consciência" (JUNG, 1987, p. 3).

Além dessa definição de inconsciente pessoal, a teoria analítica de Jung utiliza-se do conceito de inconsciente coletivo. Próprio da psicologia analítica, essa estrutura recebe o nome também de inconsciente transpessoal, sendo considerado um depósito de traços de memória latentes herdados de um passado ancestral. De acordo com Hall, Lindzey e Campbell (2000), o inconsciente coletivo é o resíduo psíquico da evolução humana, acumulado, em decorrência de repetidas experiências ao longo de várias gerações. Para Guerreiro, Casado e Bio (2004, p.5), "o inconsciente coletivo funciona, na interpretação psicológica, como denominador comum que reúne e explica numerosos fatos impossíveis de entender no momento atual da ciência". Ao discorrer acerca do inconsciente coletivo, Jung (2000, p. 54) expõe que:

à diferença da natureza pessoal da psique consciente, existe um segundo sistema psíquico, de caráter coletivo, não-pessoal, ao lado do nosso consciente, que por sua vez é de natureza inteiramente pessoal e que - mesmo quando lhe acrescentamos como apêndice o inconsciente pessoal - consideramos a única psique passível de experiência. $O$ inconsciente coletivo não se desenvolve individualmente, mas é herdado. Ele consiste de formas preexistentes, arquétipos, que só secundariamente podem tornar-se conscientes, conferindo uma forma definida aos conteúdos da consciência.

Essas duas regiões da mente inconsciente podem fornecer explicações para uma gama de acontecimentos da vida cotidiana e podem também ser muito úteis se bem utilizadas. Tendo em vista que se tratam de conteúdos subliminares esquecidos ou ignorados e que se têm à disposição saberes e experiências de incontáveis séculos armazenados em estruturas arquetípicas, se esses saberes e experiências forem desprezados ou mal utilizados pelo ego, provocam perturbações ou distúrbios nos processos racionais conscientes (JUNG, 2007). Tais perturbações explicam as fobias, os delírios e outras irracionalidades que se originam de processos inconscientes negligenciados (JUNG, 2007).

Com base nessas informações, pode-se depreender que o inconsciente coletivo, por meio dos arquétipos, pode esclarecer muitas decisões ou escolhas realizadas pelos indivíduos. Esses componentes estruturais do inconsciente coletivo, além de receber o nome de arquétipos, podem ser chamados de dominantes, imagens primordiais, imagos, imagens mitológicas e padrões de comportamento. Um arquétipo é uma forma universal de pensamento que contém uma forte carga de emoção (HALL; LINDZEY; CAMPBELL, 2000). Complementarmente, Morgan (1996) trata por arquétipos um dos aspectos mais característicos da análise junguiana e que significa em sua essência "modelo original", desempenhando um papel crítico de interligação do indivíduo com seu inconsciente coletivo, perfazendo assim, padrões que estruturam os pensamentos humanos e ordenam o mundo. $\mathrm{O}$ conceito puro sobre arquétipo de Jung (2007, p. 57), assenta-se na seguinte pressuposição subjacente:

\footnotetext{
logo, neste estágio mais adiantado do tratamento, em que as fantasias não repousam mais sobre as reminiscências pessoais, trata-se da manifestação da camada mais profunda do inconsciente, onde jazem adormecidas as imagens humanas universais e originárias. Essas imagens ou motivos denominei-os arquétipos (ou então "dominantes") .
}

Porém, Jung (2000) adverte que o arquétipo é uma forma herdada e não uma ideia herdada, e que essa última corresponde tão somente a instintos determinados por esse 
arquétipo legado. Adicionalmente, Morgan (1996) expõe que os arquétipos servem de importante ponto de partida sob o qual a compreensão humana do mundo é organizada.

\subsection{Inconsciente Próprio de um Grupo}

De acordo com Guerreiro, Frezatti e Casado (2006), o inconsciente coletivo é um conceito universal, independentemente de raça, época ou religião, diferentemente do inconsciente e consciente pessoal que são próprios de cada indivíduo. Portanto, quando se efetuam considerações sobre arquétipos, o entendimento dessas estruturas é universalmente aceito por todos, são formas-pensamento de uso comum e unânimes. Um exemplo claro de um padrão arquetípico é o que Jung (2000) chamou de arquétipo "sombra", consistindo nos instintos animais que os indivíduos herdaram em sua evolução das formas inferiores de vida, sendo o lado obscuro do ser humano, uma imagem comum, que está presente em todas as pessoas em maior ou menor intensidade.

Apesar disso, pode-se verificar que determinados agrupamentos humanos também possuem formas-pensamento próprias em suas parcerias firmadas, nas quais se poderia dizer que age um inconsciente coletivo correspondente àquele grupo, estruturados por arquétipos presentes naquela determinada cultura. Com base nessas argumentações, o presente ensaio propõe uma extensão conceitual, utilizando-se dessa breve revisão teórica para referir-se ao inconsciente coletivo da contabilidade gerencial, como sendo os reflexos condicionados por uma assimilação cultural exaustiva e muitas vezes incontestável, difícil de ser modificada por estar legitimada nas organizações como arquétipos. Se faz mister salientar que, tal denominação é inspirada nos conceitos junguianos para melhor facilitar as reflexões presentes neste ensaio, mas de modo algum, chega a ter a magnitude que Jung deu aos termos utilizados em sua Psicologia Analítica.

Para Guerreiro, Casado e Bio (2004), nas atividades empresariais frequentemente observam-se fatores inconscientes atuantes, como exemplo, quando se questiona porque determinadas atividades são feitas daquela forma específica e a resposta é sempre fizemos assim. Nesse caso não se vê consciência na realização dessa tarefa, mas sim, um condicionamento e uma mecanicidade da ação de fatores inconscientes próprios daquele determinado grupo.

\section{UMA ANÁLISE CRÍTICO-REFLEXIVA EM BUSCA DA RELEVÂNCIA PERDIDA}

Nesse tópico da discussão foi desenvolvida uma reflexão acerca da possível relação existente entre a contabilidade gerencial e o enfoque junguiano na postura do profissional contábil. Para alcançar essa meta, o estudo propôs a interação entre as diversas estruturas da personalidade componentes da teoria analítica psicológica e a realidade organizacional cotidiana, mergulhando no inconsciente coletivo da contabilidade gerencial, por meio de alegorias e relações simplificadas habituais, que melhorem a compreensão dessas analogias.

\subsection{Revisitando a Caverna de Platão: a Contabilidade Gerencial como uma Prisão Psíquica}

Há milênios Platão escreveu um texto que ainda hoje é muito difundido, intitulado "Mito da Caverna". A obra de Platão pode ser considerada atemporal, o que contribuiu para que sua utilidade não ficasse restrita à filosofia, difundindo-se também nas demais ciências. Morgan (1996), por exemplo, utilizou-se dessa alegoria para estudar as organizações como prisões psíquicas e esse ensaio revisita essa abordagem para um melhor entendimento da ação dos fatores inconscientes na escolha dos artefatos contábeis gerenciais e na contabilidade gerencial em sua amplitude, pois se concorda com as palavras de Latour (2004, p. 27) de que, "para andar rápido, mas permanecer preciso, nada mais forte que um mito". 
Imagina-se uma caverna separada do mundo externo por um alto muro, cuja entrada permite a passagem da luz exterior. Desde seu nascimento, geração após geração, seres humanos ali vivem acorrentados, sem poder mover a cabeça para a entrada, nem se locomover, forçados a olhar apenas a parede do fundo, e sem nunca terem visto o mundo exterior e nem a luz do sol. Acima do muro, uma réstia de luz exterior ilumina o espaço habitado pelos prisioneiros, fazendo com que as coisas que se passam no mundo exterior sejam projetadas como sombras nas paredes do fundo da caverna. Por trás do muro, pessoas passam conversando e carregando nos ombros figuras de homens, mulheres, animais cujas sombras são projetadas na parede da caverna. Os prisioneiros julgam que essas sombras são as próprias coisas externas, e que os artefatos projetados são os seres vivos que se movem e falam (PLATÃO, 2000).

Um dos prisioneiros, tomado pela curiosidade, decide fugir da caverna. Fabrica um instrumento com o qual quebra os grilhões e escala o muro. Sai da caverna, e no primeiro instante fica totalmente cego pela luminosidade do sol, com a qual seus olhos não estão acostumados; pouco a pouco, habitua-se à luz e começa a ver o mundo. Encanta-se, deslumbra-se, tem a felicidade de, finalmente, ver as próprias coisas, descobrindo que, em sua prisão, viu apenas sombras. Deseja ficar longe da caverna e só voltar a ela se for obrigado, para contar o que viu e libertar os demais. Assim como a subida foi penosa, porque o caminho era íngreme e a luz ofuscante, também o retorno será penoso, pois será preciso habituar-se novamente às trevas, o que é muito mais difícil do que se habituar à luz. De volta à caverna, o prisioneiro não estará adaptado àquela situação inicial e não saberá mover-se nem falar de modo compreensível com os outros, não será acreditado por eles e correrá o risco de ser morto pelos que jamais abandonaram a caverna (PLATÃO, 2000).

Analogamente, verifica-se uma diversidade de fatores que impactam as escolhas dentro das organizações. A primeira delas é que, inconscientemente, realizam-se atividades de forma mecanicista e repetitiva; da mesma maneira que os prisioneiros da caverna de Platão eram forçados a olhar somente as sombras e fazer daquilo que os olhos fitassem sua própria realidade, também há organizações que forçam seus colaboradores a olhar a realidade institucionalizada sem questioná-la, exercendo suas funções com um automatismo similar às máquinas programadas para executar tarefas específicas. Portanto, há ocasiões em que o profissional contábil quer aplicar os modelos teóricos que conhece com o intuito de alavancar a qualidade da informação produzida, mas sofre resistência da própria organização em que atua e acaba por ter que se submeter à presença dos "arquétipos" impostos pelo grupo social ao qual pertence, corroborando assim com a visão desvelada que, "somos biologicamente o espaço psíquico e espiritual que vivemos, seja como membros de uma cultura ou como resultado de nosso viver individual na reflexão que, inevitavelmente, nos transforma porque transforma nosso espaço relacional" (MATURANA, 2001, p. 121).

Uma segunda análise pode ser feita em contraposição à primeira, quando o próprio profissional não quer mudar suas atitudes e não tem interesse em enxergar novos horizontes que podem ser úteis no ambiente onde está inserido. Platão (2001, p. 211), em um dos trechos da narração do "Mito da Caverna", questiona "portanto, se alguém o forçasse a olhar para a própria luz, doer-lhe-iam os olhos e voltar-se-ia, para buscar refúgio junto dos objetos para os quais podia olhar, e julgaria ainda que estes eram na verdade mais nítidos do que os que lhe mostravam?". Essa citação esclarece que, não raras vezes, sabe-se o que deve ser feito, mas, inconscientemente, devido aos arquétipos já existentes e a cultura já enraizada como sendo a única realidade existente, esquece-se que poderiam ser testados outros artefatos, capazes de incrementar a qualidade informacional por meio de métricas de performance alternativas às tradicionais.

Seguindo ainda o raciocínio explicitado no item anterior, hoje no Brasil, fala-se no subjetivismo responsável (IUDÍCIBUS, 2007; ESPEJO et al., 2008), devido ao nível de 
julgamento que o contador deverá possuir na resolução das divergências impostas pela alteração da Lei n. 6.404/76 por meio da Lei n. 11.638/07 e da Lei n. 11.941/09. Todavia, não se pode esquecer que a prevalência da essência sobre a forma faz parte também do processo de adoção de artefatos contábeis gerenciais e que esse processo é permeado também pelos fatores inconscientes. Iudícibus (2007, p. 12) evidencia que, "a prevalência da essência sobre a forma, todavia, provoca sérios problemas para os contadores acomodados, acostumados às regrinhas de custo, da objetividade extremada, treinados mais para obedecer às normas do que para serem criativos". Salienta-se que esta postura de comodismo e a falta de interesse, algumas vezes inconscientes, podem ser um dos motivos do gap existente entre a teoria e a prática na utilização dos artefatos contábeis gerenciais.

Uma terceira vertente que se pode levar em consideração no "Mito da Caverna" é a proposição feita por Morgan (1996, p. 235), em que "a metáfora encoraja-nos a procurar fundo, abaixo da superfície, para descobrir os processos inconscientes e respectivos modelos de controle que aprisionam pessoas em esquemas insatisfatórios de existência". Passando isso para uma visão contábil, considera-se a proposição de Iudícibus $(2007$, p.16) de que, "o contador moderno, todavia, deve assumir a postura desafiadora de um viajante através do tempo, das civilizações e do espaço, na busca de novas terras e panoramas desconhecidos, ou analogamente, à descoberta do Novo Mundo que ainda nos trará muitas surpresas". Em termos práticos, essa ponderação encoraja o profissional contábil a realizar uma busca interior, no sentido de se conhecer para melhor entender suas atitudes e suas escolhas e também de comparar seus valores e crenças com os da organização em que atua, pois, não raras vezes, os indivíduos tendem a agir instintivamente sem um devido autoconhecimento seguindo as imposições das heranças atávicas (arquétipos) que os dominam.

Mais uma reflexão que pode ser extraída dessa metáfora é o fato da incompreensão que o grupo externaliza para com os indivíduos que tentam modificar o status quo. É a figura do prisioneiro que sai da caverna e sente receio de voltar porque a realidade que ele conhece é totalmente diferente daquela realidade imposta pela equipe a qual pertence. Duarte Jr. (2008) expõe que "é impossível ao indivíduo sozinho manter uma concepção discordante do universo simbólico em que está [...] alternativas a um determinado universo simbólico apenas são possíveis". Nesse sentido, observa-se que o indivíduo algumas vezes sabe que determinadas atitudes podem prejudicar as informações que servem de base para a tomada de decisões corporativa, mas sozinho em meio a todos os demais que pensam contrariamente, não consegue dar ênfase a seus ideais.

Por conseguinte, a presente reflexão crítica conduz à constatação de que esse descompasso existente na utilização dos artefatos contábeis gerenciais pode ter relações causais inconscientes por meio de arquétipos presentes nas empresas, decorrentes de uma cultura organizacional muito profunda e de processos institucionalizados difíceis de serem modificados, causados pelas posturas dos profissionais envolvidos no ambiente corporativo.

\subsection{Persona e Sombra: Informações Evidenciadas e Sonegadas em Contabilidade Gerencial}

De acordo com Hall, Lindzey e Campbell (2000, p. 91), a persona é "a personalidade pública, aqueles aspectos que apresentamos ao mundo ou que a opinião pública impõe ao indivíduo, em contraste com a personalidade privada existente por trás da fachada social". Em essência, a persona é composta pelos aspectos que os indivíduos externalizam para serem aceitos na sociedade, diante das projeções impostas pelos demais participantes dessa coletividade, mas que não necessariamente fazem parte dos papéis que essa pessoa desempenha em sua individualidade.

Analogamente, nas organizações esse fenômeno também é perceptível. No contexto social e histórico contemporâneo, a palavra excelência mudou de foco, transpondo-se de um 
valor que era duradouro e consistente, para algo efêmero e flexível (FREITAS, 2000). Juntamente com essa mutação, os diversos profissionais que fazem parte de uma equipe sentem-se comprometidos em superar as expectativas projetadas pelos seus superiores hierárquicos sobre eles, mostrando resultados positivos do ponto de vista empresarial para serem aceitos em determinada corporação.

Dentro dessa perspectiva conjuntural, Santos e Grateron (2003, p.8), em seu estudo, investigam uma metodologia utilizada por algumas empresas, denominada contabilidade criativa ou earnings management, definida pelos autores como sendo o "gerenciamento ou manuseio de resultados, com a intenção de mostrar uma imagem diferente (estável no tempo, melhor ou pior) da entidade". A existência destas práticas criativas pode modificar substancialmente a tomada de decisões por parte dos gestores, visto que as informações geradas são inexatas, ou no mínimo, diferentes das reais. Parecem supor que as técnicas de contabilidade criativa não podem ser entendidas apenas como uma forma de manipulação de resultados, mas também como alteração de dados das demonstrações contábeis que possam afetar índices ou coeficientes (SANTOS; GRATERON, 2003). Todavia, destaca-se que, apesar da presente reflexão estar pautada na contabilidade gerencial, o earnings management ocorre também na contabilidade financeira, pois o contador ou gestor sente-se incitado a oferecer informações consideradas satisfatórias aos acionistas, aos investidores, ao mercado financeiro e demais stakeholders.

Freitas (2000, p.12) expõe que, "a carreira, ou o status profissional, torna-se o elemento organizador da vida pessoal, aquilo que lhe dá sentido, auto-imagem, reconhecimento e o único referente que lhe pode permitir a expressão do sucesso e da realização profissional". Depreende-se com isso que, o profissional de contabilidade gerencial e o gestor, assim como em outras profissões, podem ser impelidos a mostrar somente as informações favoráveis ou escolher artefatos contábeis que melhor evidenciem posições cômodas, em detrimento de outros que demonstrem adequadamente as realidades operacional, financeira e econômica empresarial, em função da constante pressão por bons resultados gerenciais, na visão dos altos executivos.

Portanto, a persona aparece nesses casos como uma visão de curto prazo por parte do profissional contábil ou do gestor que está, muitas vezes, preocupado somente com a sua própria ascensão corporativa ou em mostrar tão somente para o grupo ao qual pertence que ele é digno de fazer parte daquela equipe que o legitimará pelos resultados positivos que trouxer à organização. Essa conduta oportunista por parte dos profissionais esconde outro arquétipo da teoria junguiana denominado sombra.

Para Young-Eisendrath e Dawson (2002, p. 103), a sombra é formada por "tendências, motivos e características pessoais que excluímos da consciência, deliberadamente ou não. É claro que ela é tipicamente projetada nas outras pessoas". Hall, Lindzey e Campbell (2000, p.91) esclarecem que o arquétipo sombra é "responsável pelo aparecimento, na consciência, de pensamentos, sentimentos e ações desagradáveis e socialmente repreensíveis, que podem então ser escondidos da visão pública da persona ou reprimidos no inconsciente pessoal". Por conseguinte, pode-se afirmar que esse arquétipo é representado por aspectos indesejáveis da natureza humana, apresentando-se como a base da realidade e o contrapeso da ilusão.

Por esse motivo os principais recursos da teoria junguiana são a aceitação e integração da sombra na psique humana, ou seja, o lado obscuro da personalidade de um indivíduo deve ser aceito e integrado por ele, em seu processo de individuação. $\mathrm{Na}$ contabilidade gerencial parece ocorrer o mesmo e, as informações devem ser aceitas e integradas, de forma a não apresentarem ilusões de curto prazo que possam trazer implicações de longo prazo ou descontinuidade das atividades empresariais. De maneira similar, os artefatos de contabilidade gerencial precisam ser adaptados à realidade empresarial da organização, mesmo que tal fato traga resultados que demonstrem uma situação desfavorável. 


\subsection{Anima e Animus: Relações de Gênero na Contabilidade Gerencial}

Na concepção junguiana, o ser humano é essencialmente um animal bissexual em um nível fisiológico, pois a fêmea secreta hormônios masculinos e femininos, assim como o macho. Diante disso, Jung atribui o lado feminino da personalidade do homem ao arquétipo denominado anima e, o lado masculino da personalidade da mulher ao arquétipo que designou animus (HALL; LINDZEY; CAMPBELL, 2000). Em determinadas situações, especialmente em momentos de dificuldade e estresse, essas duas personalidades interiores apoderam-se do indivíduo consciente, ou seja, um homem pode ser possuído por sua anima e se tornar, por assim dizer uma mulher inferior, caracterizada pelas atitudes rabugentas, mal-humoradas e irracionais. De modo análogo, uma mulher que sofre a possessão de seu animus, pode tornarse um homem inferior, com características de inflexibilidade, insistência e excesso de racionalidade (YOUNG-EISENDRATH; DAWSON, 2002). Reforça-se a ideia de que a classificação de anima e animus exposta nesta reflexão é baseada e enquadrada em tipificações junguianas, não resultando assim em nenhuma interpretação dos pesquisadores quando da designação dos termos "homem inferior" ou "mulher inferior" e suas qualificações.

Ao se traçar um paralelo entre esses arquétipos e a contabilidade gerencial, compreende-se que em momentos de pressão por resultados e estresse organizacional, as relações de gênero conduzidas por essas imagens arquetípicas, nesse ínterim, fazem-se presentes e afetam as escolhas dos artefatos contábeis que melhor evidenciem a realidade organizacional visando à tomada de decisões mais coerente naquele contexto. Por esse motivo, vê-se em algumas empresas contadores ou gestores retraídos, submissos e não raras vezes, irracionais, pois, são arrebatados pelo seu anima, que prevalece em suas escolhas e influencia a adoção de artefatos contábeis; noutras ocasiões o inverso pode ocorrer, quando uma contadora ou gestora é dominada pelo seu animus e apresenta características de inflexibilidade e racionalidade extremada que prejudicam as atividades na contabilidade gerencial. A teoria junguiana vê essas figuras dominantes, anima e animus, como mediadoras para o mundo inconsciente (YOUNG-EISENDRATH; DAWSON, 2002). Destarte, é importante o equilíbrio e a reconciliação entre elas.

\subsection{A Constante Luta entre o Ego e o Self: o Processo de Escolha dos Artefatos}

Jung supôs a existência de um self como sendo o sustentáculo de um processo de individuação, que faz com que cada pessoa seja única e exclusiva em suas atitudes e decisões, ou seja, o ego consciente é parte essencial e o resto é formado pelo inconsciente (YOUNGEISENDRATH; DAWSON, 2002). O conceito de self representa a descoberta mais importante de Jung (HALL; LINDZEY; CAMPBELL, 2000). De acordo com os autores, inicialmente, Jung considerava o self como sendo a personalidade total e, ao aprofundar seus estudos, concluiu que o self representa o centro da personalidade; o ponto de equilíbrio e estabilidade de cada indivíduo. Dessa forma, pode-se entender que todas as escolhas e decisões tomadas deveriam atingir o self - um foco central se fosse traçado uma linha imaginária entre a mente consciente e a mente inconsciente; é o ponto de decisão ótima ou de maximização das potencialidades decisórias.

Jung (2008) assevera que o ego é representado pelo homem do mundo, ou seja, é a presença da sombra, a prevalência da anima ou do animus, a ênfase nos valores de curto prazo, o egocentrismo característico das pessoas imediatistas, a barganha de sentimentos e atitudes (só se faz algo se tiver uma recompensa) e, principalmente a maior importância no ter em detrimento do ser. Em contrapartida, o autor defende que o self é representado pelo homem no mundo, mas sem necessariamente ter subterfúgios para conseguir chegar onde quer, sendo assim observado pelo esforço na integração da sombra, pela busca do equilíbrio entre seu anima e seu animus, pela maior ênfase que aplica nos valores morais e, notadamente 
pela maior importância do ser em detrimento do ter, buscando atingir o que Jung (2008) denomina de estado numinoso, ou seja, o estado de equilíbrio total.

Invariavelmente, o indivíduo busca superar esse eu opositor frequente, adotando comportamento castrador, por intermédio do esforço consciente para suprimi-lo, o que redunda num grande fracasso, porque o pólo que orienta o outro eu permanece vivo, embora disfarçado pela aparência que se adquire. Por isso, o objetivo essencial da existência humana, do ponto de vista psicológico, na visão junguiana, é facultar ao indivíduo a aquisição de sua totalidade, o estado numinoso, que lhe faculta o perfeito equilíbrio dos pólos opostos (FRANCO; ÂNGELIS, 2009).

Ao chegarem próximos de atingirem o self os indivíduos libertam-se das prisões psíquicas nas quais estão inseridos, uma vez que ponderam com efetividade as escolhas a serem feitas. Portanto, uma das alternativas para a resolução do problema da relevância perdida, proposta por Johnson e Kaplan (1987) está em quem escolhe esses artefatos contábeis gerenciais. Acredita-se que esse indivíduo deve soltar as amarras psíquicas que o condicionam dentro de um ambiente que lhe exige comportamentos mecanicistas e repetitivos como se não fosse dotado de raciocínio. Deve-se enfatizar que organizações são diferentes umas das outras e, portanto, cada qual possui um self próprio a ser determinado pelas pessoas que a constituem e pelos padrões arquetípicos que as definem.

Não menos importante nesse contexto organizacional é o subjetivismo responsável e a postura crítica do profissional contábil. Todos os artefatos de contabilidade gerencial devem ser postos em prova e necessitam serem avaliados levando-se em consideração seus efeitos para o processo decisório. A ausência de reflexão e análise torna a utilização do arcabouço conceitual contábil míope, mecânica e repetitiva; contrapondo-se a isso, a adoção indistinta de qualquer técnica gerencial sem a devida análise crítica pode trazer custos desnecessários à empresa por estar produzindo informações dispensáveis com base em modelos que não atendem às necessidades reais da entidade.

Outro modo de reduzir o descompasso existente entre a teoria e a prática no uso efetivo dos artefatos contábeis gerenciais é por meio da conscientização dos indivíduos, transferindo para o nível da consciência de cada profissional a importância da utilização desse ferramental para a maximização do valor empresarial e também os fazendo entender que a teoria fornece embasamento para toda a prática. Portanto, essa evolução teórica que está ocorrendo nas técnicas em contabilidade gerencial deve ser seguida no exercício profissional sob pena de se perderem informações valiosas para o processo decisório.

Por fim, sugere-se que depois de realizadas essas análises críticas, sejam planejadas ações que subsidiem a sadia criação de novos hábitos e rotinas, gerando um novo inconsciente coletivo, para que artefatos de contabilidade gerencial alternativos possam integrar o rol de práticas contábeis, buscando a melhor alternativa e a decisão ótima para o contexto daquele grupo empresarial, na busca incessante do self organizacional.

\section{CONCLUSÕES}

Pode-se depreender por meio das manifestações expostas no presente ensaio, que a postura do profissional da contabilidade influencia as escolhas dos artefatos contábeis gerenciais. Esse cenário pode gerar uma explicação plausível para o descompasso existente entre a crescente sofisticação desses artefatos e sua utilização na prática corporativa, devido aos aspectos inconscientes da psique humana, que se encontram na cultura da organização e na institucionalização das práticas empresariais que as tornam legitimadas no ambiente empresarial. Contudo, cabe ressaltar que o assunto é complexo e exige reflexões mais apuradas de cunho empírico para confrontar a teoria ora defendida.

A temática tem uma importância igualmente de caráter epistemológico, no sentido de trazer para a contabilidade outra forma de apreender a realidade, saindo do contexto 
eminentemente funcionalista e tentando fornecer uma visão mais crítica dos fatos que ocorrem nas organizações. Diante desse fato, há que se destacar a relevância das pesquisas embasarem-se em teorias para formulação de reflexões e não somente em conceitos e definições que não traduzem o aprofundamento necessário das discussões. Nesse contexto, a interdisciplinaridade tem papel fundamental na evolução da ciência contábil.

O caráter subjetivo das manifestações expostas neste ensaio merece cautela em suas ponderações, pois se tratam de conceitos referentes à psique humana que, na maioria das vezes, é fácil de ser sentido, mas difícil de ser traduzido em palavras e compreendido pelos indivíduos, porquanto depende de um potencial de abstração e reflexão crítica elevados. Todavia, cumpre ressaltar que ao se entender a subjetividade das ações contribui-se para explicar o porquê de fatos concretos não definidos por modelos pré-fixados, dependendo da personalidade dos indivíduos que interagem no contexto organizacional.

Salienta-se que esta investigação possui implicações acadêmicas e profissionais. Academicamente, o estudo expôs outra ótica elucidativa da adoção dos artefatos de contabilidade gerencial, que não a tradicional racionalidade econômica. Tal fato demonstra a interdisciplinaridade e a busca por novos argumentos que sustentem teoricamente os estudos em contabilidade gerencial e desvela um ambiente ainda embrionário e com muitas possibilidades de pesquisas unindo os conceitos próprios da psicologia e da contabilidade para um melhor entendimento da temática analisada. Profissionalmente, o estudo refletiu sobre as questões relativas à postura do profissional de contabilidade gerencial sob um enfoque antropo-sócio-psicológico, que tenta resgatar a concepção humana que está por trás das tomadas de decisões e das escolhas dos artefatos contábeis gerenciais, por meio do melhor entendimento do funcionamento da psique humana.

Por fim, destaca-se a limitação da dificuldade de operacionalização dos constructos da pesquisa relacionados aos fatores inconscientes para uma consequente investigação empírica sobre a temática exposta e sugere-se que a comunidade científica empenhe-se em encontrar uma forma de fazê-lo em pesquisas futuras, para uma melhor visualização das variáveis intervenientes nesse processo psicológico da contabilidade gerencial.

\section{REFERÊNCIAS}

ALLINSON, Christopher W.; HAYES, John. The cognitive style index: a measure of intuition-analysis for organizational research. Journal of Management Studies. v. 33, n. 1, p. 119-135, Jan. 1996. http://dx.doi.org/10.1111/j.1467-6486.1996.tb00801.x

ALVESSON, Mats; DEETZ, Stanley. Teoria crítica e abordagens pós-modernas para estudos organizacionais. In: CLEGG, Stewart R; HARDY, Cynthia; NORD, Walter R. Handbook de Estudos Organizacionais: modelos de análise e novas questões em estudos organizacionais. 1 ed. São Paulo: Atlas, 2007. Vol. 1.

ATKINSON, Anthony A.; BANKER, Rajiv D.; KAPLAN, Robert S.; YOUNG, S. Mark. Contabilidade Gerencial. 2. ed. São Paulo: Atlas, 2008.

BAINES, Annette; LANGFIELD-SMITH, Kim. Antecedents to management accounting change: a structural equation approach. Accounting, Organizations and Society. v. 28, p. 675-698, 2003. http://dx.doi.org/10.1016/S0361-3682(02)00102-2

BURNS, John; SCAPENS, Robert W. Conceptualizing management accounting change: an institutional framework. Management Accounting Research. v. 11, p. 3-25, 2000.

CHENG, Mandy M.; LUCKETT, Peter F.; SCHULZ, Axel K-D. The effects of cognitive style diversity on decision-making dyads: an empirical analysis in the context of a complex task. Behavioral Research in Accounting. v. 15, p. 39-62, 2003. http://dx.doi.org/10.1006/mare.1999.0119 
COVALESKI, Mark A.; DIRSMITH, Mark W.; SAMUEL, Sajay. Managerial accounting research: the contributions of organizational and sociological theories. Journal of Management Accounting Research. v. 8, p. 1-35, 1996.

DUARTE Jr., João Francisco. O que é realidade? Coleção primeiros passos. São Paulo: Brasiliense, 2008.

ELLENBERGER, Henri F. The discovery of the unconscious: the history and evolution of dynamic psychiatry. New York: Basic Books, 1970.

ESPEJO, Márcia Maria dos Santos Bortolocci. Perfil dos atributos do sistema orçamentário sob a perspectiva contingencial: uma abordagem multivariada. São Paulo, 2008. Tese (Doutorado em Ciências Contábeis) - Programa de Pós-Graduação em Ciências Contábeis, Faculdade de Economia, Administração e Contabilidade da Universidade de São Paulo, 2008.

ESPEJO, Márcia Maria dos Santos Bortolocci; FREZATTI, Fabio; CRUZ, Ana Paula Capuano da; COSTA, Flaviano. Uma visão institucional do subjetivismo responsável na adoção das normas internacionais de contabilidade: uma análise crítico-reflexiva sobre os inibidores à convergência no Brasil. In: CONGRESSO DE CONTABILIDADE E AUDITORIA, 12., 2008, Aveiro. Anais... Aveiro: ISCA, 2008.

ESPEJO, Márcia Maria dos Santos Bortolocci; CRUZ, Ana Paula Capuano da; COSTA, Flaviano; ALMEIDA, Lauro Brito de. Uma análise crítico-reflexiva da compreensão da adoção dos artefatos de contabilidade gerencial sob uma lente alternativa: a contribuição de abordagens organizacionais. Revista Contabilidade e Organizações, v. 3, n. 5, p. 25-43, jan./abr. 2009.

FRANCO, Divaldo Pereira; ÂNGELIS, Joanna. Em busca da verdade. Salvador: Leal, 2009.

FREITAS, Maria Ester de. Contexto social e imaginário organizacional moderno. RAE. Revista de Administração de Empresas, São Paulo, v. 40, n. 2, p. 6-15, abr./jun. 2000.

FREZATI, Fábio. Management accounting profile of firms located in Brazil: a field study. Brazilian Administration Review, Curitiba. v. 2, n. 1, p. 73-87, Jan./Jun. 2005. http://dx.doi.org/10.1590/S1807-76922005000100006

FREZATI, Fábio. Orçamento empresarial: planejamento e controle gerencial. São Paulo: Atlas, 2006.

GALLÉN, Tiina. Managers and strategic decisions: does the cognitive style matter? Journal of Management Development. v. 25, n. 2, p. 118-133, 2006.

GARDNER, William L.; MARTINKO, Mark J. Using the myers-briggs type indicator to study managers: a literature review and research agenda. Journal of Management. v. 22, n. 1, p. 45-83, 1996. http://dx.doi.org/10.1177/014920639602200103

GOLEMAN, Daniel. Inteligência emocional. Rio de Janeiro: Objetiva, 2001.

GRANLUND, Markus; LUKKA, Kari. It's a small world of management accounting practices. Journal of Management Accounting Research. v. 10, p. 153-179, 1998. http://dx.doi.org/10.1006/mare.2000.0151

GRANLUND, Markus. Towards explaining stability in and around management accounting systems. Management Accounting Research. v. 12, n. 2, p. 141-146, Jun. 2001.

GUERREIRO, Reinaldo; FREZATTI, Fábio; CASADO, Tânia. Em busca de um melhor entendimento da contabilidade gerencial através da integração de conceitos da psicologia, cultura organizacional e teoria institucional. Revista Contabilidade \& Finanças, São Paulo, 
Edição Comemorativa, v. 17, p. 7-21, set. 2006. http://dx.doi.org/10.1590/S151970772006000400002

GUERREIRO, Reinaldo; FREZATTI, Fábio; LOPES, Alexandro Broedel; PEREIRA, Carlos Alberto. $\mathrm{O}$ entendimento da contabilidade gerencial sob a ótica da teoria institucional. O\&S. Organizações \& Sociedade, v. 12, n. 35, p. 91-106, out./dez. 2005.

GUERREIRO, Reinaldo; CASADO, Tânia; BIO, Sérgio R. Some reflections on the archetypes in cost accounting: an exploratory study. Journal of Applied Management Accounting Research. v. 2, n. 1, p. 41-54, 2004.

HALL, Calvin S.; LINDZEY, Gardner; CAMPBELL, John B. Teorias da personalidade. 4. ed. Porto Alegre: Artmed, 2000.

HALL, Matthew. The effect of comprehensive performance measurement systems on role clarity, psychological empowerment and managerial performance. Accounting, $\begin{array}{lllllll}\text { Organizations and } & \text { Society. } & \text { v. } & 33, & \text { p. } & 141-163, & \end{array}$ http://dx.doi.org/10.1016/j.aos.2007.02.004

HOUGH, Jill R; OGILVIE, Dt. An empirical test of cognitive style and strategic decision outcomes. Journal of Management Studies. v. 42, n. 2, p. 417-448, mar., 2005. http://dx.doi.org/10.1111/j.1467-6486.2005.00502.x

HORNGREN, Charles T.; SUNDEM, Gary L.; STRATTON, William O. Introduction to management accounting. 10. ed. Upper Saddle River, Prentice Hall, 1996.

ITTNER, Christopher D.; LARCKER, David F. Empirical managerial accounting research: are we just describing management consulting practice? The European Accounting Review. v. 11, n. 3, p. 787-793, Out. 2002. http://dx.doi.org/10.1080/0963818022000047082

IUDÍCIBUS, Sérgio de. Ensaio sobre algumas raízes profundas da contabilidade, em apoio aos princípios fundamentais. Revista de Contabilidade e Organizações, v. 1, n. 1, p. 9-16, set./dez. 2007.

JOHNSON, Thomas; KAPLAN, Robert S. Relevance lost: the rise and fall of management accounting. Boston: Harvard Business School Press, 1987.

JUNG, Carl Gustav. Psicologia do inconsciente. 17. ed. Petrópolis: Vozes, 2007.

JUNG, Carl Gustav. O eu e o inconsciente. 19. ed. Petrópolis: Vozes, 1987.

JUNG, Carl Gustav. Os arquétipos e o inconsciente coletivo. 4. ed. Petrópolis: Vozes, 2000.

JUNG, Carl Gustav. Fundamentos da psicologia analítica. 14. ed. Petrópolis: Vozes, 2008.

JUNG, Carl Gustav. Chegando ao inconsciente. In: JUNG, Carl Gustav; FREEMAN, John; VON FRANZ, Marie-Louise; HENDERSON, Joseph L.; JACOBI, Jolande; JAFFÉ, Aniela. O homem e seus símbolos. 2 ed. Rio de Janeiro: Nova Fronteira, 2008.

LATOUR, Bruno. Políticas da natureza: como fazer ciência na democracia. Bauru: EDUSC, 2004.

LOPES, Alexsandro Broedel. A teoria dos contratos, governança corporativa e contabilidade. In: LOPES, Alexsandro Broedel; IUDÍCIBUS, Sérgio de. Teoria avançada da contabilidade. São Paulo: Atlas, 2004.

MATURANA, Humberto. A ontologia da realidade. Belo Horizonte: Editora UFMG, 2001.

MORGAN, Gareth. Imagens da organização. São Paulo: Atlas, 1996.

OLIVER, Christine. Strategic responses to institutional processes. Academy of Management 
Review. v. 16, n. 1, p. 145-179, Jan. 1991.

OTLEY, David. Management control in contemporary organizations: towards a wider framework. Management Accounting Research. v. 5, p. 289-299, 1994. http://dx.doi.org/10.1006/mare.1994.1018

OYADOMARI, José Carlos Tiomatsu; CARDOSO, Ricardo Lopes; MENDONÇA, Octavio R.; LIMA, Mariana Ponciano. Fatores que influenciam a adoção de artefatos de controle gerencial nas empresas brasileiras: um estudo exploratório sob a ótica da teoria institucional. Revista Contabilidade e Organizações, v. 2, n. 2, p. 55-70, jan./abr. 2008.

PADOVEZE, Clóvis Luís. Controladoria estratégica e operacional: conceitos, estrutura e aplicação. São Paulo: Pioneira Thomson Learning, 2003.

PLATÃO. A república. São Paulo: Martin Claret, 2000.

QUELLETTE, Judith A; WOOD, Wendi. Habit and intention in everyday life: the multiple processes by which past behavior predicts future behavior . Psychological Bulletin. v. 124, n. 1, p. 54-74, 1998. http://dx.doi.org/10.1037/0033-2909.124.1.54

SANTOS, Ademilson R. dos; ALMEIDA, Lauro B. de; CROZATTI, Jaime. Considerações sobre o processo de institucionalização de área organizacional de controladoria: uma abordagem de interação da visão da psicologia humana, cultura organizacional à teoria institucional. In: EnANPAD, 31., 2007, Rio de Janeiro. Anais... Rio de Janeiro: ANPAD, 2007. CD-ROM.

SANTOS, Ariovaldo dos; GRATERON, Ivan R. G. Contabilidade criativa e responsabilidade dos auditores. Revista Contabilidade \& Finanças, São Paulo, n. 32, p. 7-22, maio/ago. 2003. http://dx.doi.org/10.1590/S1519-70772003000200001

SOUTES, Dione Olesczuk. Uma investigação do uso de artefatos da contabilidade gerencial por empresas brasileiras. São Paulo, 2006. Dissertação (Mestrado em Contabilidade) - Programa de Pós-Graduação em Controladoria e Contabilidade da Universidade de São Paulo, 2006.

SOUTES, Dione Olesczuk; GUERREIRO, Reinaldo. Uma investigação do uso de artefatos de contabilidade gerencial em empresas brasileiras. In: EnANPAD, 31., 2007, Rio de Janeiro. Anais... Rio de Janeiro: ANPAD, 2007. CD-ROM.

SOUZA, Marcos A.; LISBOA, Lázaro P.; ROCHA, Welington. Práticas de contabilidade gerencial adotadas por subsidiárias brasileiras de empresas multinacionais. Revista Contabilidade \& Finanças, São Paulo, n. 32, p. 40-57, maio/ago. 2003. http://dx.doi.org/10.1590/S1519-70772003000200003

YOUNG-EISENDRATH, Polly; DAWSON, Terence. Manual de Cambridge para estudos Junguianos. Porto Alegre: Artmed Editora, 2002. 